\title{
Peripheral but Not Hepatic Insulin Resistance in Mice with One Disrupted Allele of the Glucose Transporter Type 4 (GLUT4) Gene
}

\author{
Luciano Rossetti, ${ }^{\star}$ Antine E. Stenbit, ${ }^{\ddagger}$ Wei Chen, ${ }^{\star}$ Meizhu Hu, ${ }^{\star}$ Nir Barzilai, ${ }^{\star}$ Ellen B. Katz, ${ }^{\ddagger}$ and Maureen J. Charron ${ }^{\ddagger}$ \\ $*$ Department of Medicine, and ${ }^{\ddagger}$ Department of Biochemistry, Diabetes Research and Training Center, Albert Einstein College of \\ Medicine, Bronx, New York 10461
}

\section{Abstract}

Glucose transporter type 4 (GLUT4) is insulin responsive and is expressed in striated muscle and adipose tissue. To investigate the impact of a partial deficiency in the level of GLUT4 on in vivo insulin action, we examined glucose disposal and hepatic glucose production (HGP) during hyperinsulinemic clamp studies in 4-5-mo-old conscious mice with one disrupted GLUT4 allele [GLUT4 $(+/-)$ ], compared with wild-type control mice [WT $(+I+)]$. GLUT4 $(+I-)$ mice were studied before the onset of hyperglycemia and had normal plasma glucose levels and a 50\% increase in the fasting $(6 \mathrm{~h})$ plasma insulin concentrations. GLUT4 protein in muscle was $\sim 45 \%$ less in GLUT4 $(+I-)$ than in WT $(+I+)$. Euglycemic hyperinsulinemic clamp studies were performed in combination with $\left[3-{ }^{3} \mathrm{H}\right]$ glucose to measure the rate of appearance of glucose and HGP, with $\left[\mathrm{U}-{ }^{14} \mathrm{C}\right]$-2-deoxyglucose to estimate muscle glucose transport in vivo, and with $\left[\mathrm{U}-{ }^{14} \mathrm{C}\right]$ lactate to assess hepatic glucose fluxes.

During the clamp studies, the rates of glucose infusion, glucose disappearance, glycolysis, glycogen synthesis, and muscle glucose uptake were $\sim 55 \%$ decreased in GLUT4 $(+I-)$, compared with WT $(+I+)$ mice. The decreased rate of in vivo glycogen synthesis was due to decreased stimulation of glucose transport since insulin's activation of muscle glycogen synthase was similar in GLUT4 $(+I-)$ and in WT $(+I+)$ mice. By contrast, the ability of hyperinsulinemia to inhibit HGP was unaffected in GLUT4 $(+/-)$. The normal regulation of hepatic glucose metabolism in GLUT4 $(+/-)$ mice was further supported by the similar intrahepatic distribution of liver glucose fluxes through glucose cycling, gluconeogenesis, and glycogenolysis.

We conclude that the disruption of one allele of the GLUT4 gene leads to severe peripheral but not hepatic insulin resistance. Thus, varying levels of GLUT4 protein in striated muscle and adipose tissue can markedly alter whole body glucose disposal. These differences most likely account for the interindividual variations in peripheral insulin action. (J. Clin. Invest. 1997. 100:1831-1839.) Key words: GLUT4 • insulin resistance - glucose transport • hepatic glucose production $\cdot$ gluconeogenesis

Address correspondence to Luciano Rossetti, M.D., Division of Endocrinology, Department of Medicine, Albert Einstein College of Medicine, 1300 Morris Park Avenue, Bronx, NY 10461. Phone: 718430-4118 or 718-430-4215; FAX: 718-430-8557; E-mail: rossetti@ aecom.yu.edu

J. Clin. Invest.

(C) The American Society for Clinical Investigation, Inc. 0021-9738/97/10/1831/09 \$2.00

Volume 100, Number 7, October 1997, 1831-1839

http://www.jci.org

\section{Introduction}

The facilitative glucose transporter type 4 (GLUT4) ${ }^{1}$ is the isoform selectively expressed in insulin target tissues such as striated muscle and adipose cells (1-4), and is largely responsible for the marked increase in glucose transport after insulin administration (3-5). Under basal conditions, GLUT4 resides in an intracellular compartment and, in skeletal muscle, is translocated to the plasma membrane and to the $T$ tubules after tissue exposure to insulin $(5,6)$. Much experimental evidence indicates that stimulation of glucose transport is the rate-limiting step in peripheral insulin action under most physiological settings $(4,7-11)$. Furthermore, an impairment in insulin stimulation of glucose transport or phosphorylation has been recognized as the rate-determining defect in both individuals with non-insulin-dependent diabetes mellitus (NIDDM) $(9,12-15)$ and in young siblings of two NIDDM parents with normal glucose tolerance (12).

Although it is unlikely that mutations in the GLUT4 gene are responsible for the insulin resistance in a significant portion of patients with NIDDM $(4,16,17)$, the level of GLUT4 expression varied greatly among study subjects in all published reports $(16,18,19)$ and, in individuals with normal glucose tolerance, a strong correlation has been shown between GLUT4 protein abundance in skeletal muscle and the rates of glucose disposal during insulin clamp studies $(16,19)$. Conversely, it is now well established that GLUT4 expression is not consistently decreased in patients with $\operatorname{NIDDM}(16,20,21)$ and the above correlation between peripheral insulin action and muscle GLUT4 is lost once diabetes mellitus is established $(16,20)$. It has long been recognized that large variations exist in insulin-stimulated glucose uptake within healthy individuals with normal glucose tolerance (22). Based on the above observations, it may be hypothesized that moderate variations in the level of GLUT4 protein in skeletal muscle may be responsible for the large variability in peripheral insulin sensitivity in individuals with normal glucose tolerance. However, it is presently unknown whether such a moderate decrease in the level of gene expression of this transporter would be sufficient to generate a severe impairment in insulin's ability to promote whole body glucose disposal.

Insulin resistance in NIDDM involves defects in glucose transport/phosphorylation, glycogen synthesis, and glucose oxidation (23-29). Defective activation of skeletal muscle glycogen synthase by insulin has also been demonstrated by several laboratories $(23,29,30)$, and this defect has been shown to be independent of the associated decrease in the rate of glucose

1. Abbreviations used in this paper: GLUT4, glucose transporter type 4; HGP, hepatic glucose production; NIDDM, non-insulin-dependent diabetes mellitus; PEP, phosphoenolpyruvate; Rd, rate of glucose disappearance. 
uptake (24). Conversely, recent studies using nuclear magnetic resonance spectroscopy have demonstrated that the decreased rate of glycogen synthesis in a group of NIDDM patients studied under hyperglycemic and hyperinsulinemic conditions could be entirely accounted for by the defect in glucose transport/phosphorylation $(11,31)$. Thus, it is presently unknown whether a primary defect in the rate of glucose transport would lead to secondary alterations in the intracellular partitioning of glucose fluxes, or to a defect in the activation of glycogen synthase by insulin.

Hepatic and peripheral insulin resistance are generally tightly associated (27) and recent evidence indicates that peripheral actions of insulin mediate a large portion of its effects on hepatic glucose fluxes (32-34). It has also been observed that marked increases in the rates of peripheral glucose disposal are associated with concomitant increases in the rate of hepatic gluconeogenesis during hyperinsulinemic clamp studies $(35,36)$. However, a dissociation between peripheral and hepatic insulin resistance has been observed in a recent study in patients with NIDDM (37), in siblings of two NIDDM parents $(25,30,38)$, and in essential hypertension $(39,40)$. Whether a primary defect in the action of insulin on peripheral glucose disposal might lead to hepatic insulin resistance and/or to alterations in the intrahepatic distribution of glucose fluxes remains to be delineated.

To address these questions, peripheral and hepatic insulin action were examined in conscious mice with a disrupted GLUT4 allele [GLUT4 (+/-)] (41) that presented a decrease in the abundance of GLUT4 protein in skeletal muscle and adipose tissue.

\section{Methods}

Animals. Two groups of male mice were studied. Group 1 included six GLUT4 (+/-) mice and group 2 included eight wild-type littermate control mice [WT $(+/+)]$. GLUT4 $(+/-)$ mice were derived using homologous recombination and embryonic stem cell technology (41). Mice were genotyped by Southern blot analysis after extraction of tail DNA. At 4-5 mo of age, all mice (30-35 g) were anesthetized with chloral hydrate ( $400 \mathrm{mg} / \mathrm{kg}$ body wt i.p.), and an indwelling catheter was inserted into the right internal jugular vein, as previously described $(36,42,43)$. The venous catheter was used for the multiple infusions, while blood samples were obtained from the tail vein. Mice were studied 4-5 d after surgery.

Euglycemic hyperinsulinemic clamp studies. Studies were performed in awake, unrestrained, chronically catheterized mice using the insulin clamp technique $(34,42,44)$, in combination with HPLCpurified $\left[3-{ }^{3} \mathrm{H}\right]$ glucose, $\left[\mathrm{U}-{ }^{14} \mathrm{C}\right]$-2-deoxyglucose, and $\left[\mathrm{U}-{ }^{14} \mathrm{C}\right]$ lactate infusions, as previously described $(8,36,42,45)$. Food was removed for $6 \mathrm{~h}$ before the in vivo protocol. All studies lasted $170 \mathrm{~min}$ and included an 80-min basal period for assessment of the rates of glucose turnover and a 90-min hyperinsulinemic clamp period. $80 \mathrm{~min}$ before starting the glucose/insulin infusions, a prime-continuous infusion of HPLC-purified $\left[3-{ }^{3} \mathrm{H}\right]$ glucose $(10 \mu \mathrm{Ci}$ bolus, $0.1 \mu \mathrm{Ci} / \mathrm{min}$; New England Nuclear, Boston, MA) was initiated and maintained throughout the remainder of the study. A bolus of $\left[\mathrm{U}-{ }^{14} \mathrm{C}\right]$-2-deoxyglucose $(10 \mu \mathrm{Ci})$ was injected $45 \mathrm{~min}$ before the end of the study. [U- $\left.{ }^{14} \mathrm{C}\right] \mathrm{lac}-$ tate $(5 \mu \mathrm{Ci}$ bolus $/ 0.25 \mu \mathrm{Ci} / \mathrm{min})$ was infused during the last $10 \mathrm{~min}$ of the study.

The protocol followed during the insulin clamp study was similar to that previously described in rats $(8,44,45)$ and mice $(36,42)$. Briefly, a prime-continuous infusion of regular insulin $(18 \mathrm{mU} / \mathrm{kg}$ per min) was administered, and a variable infusion of a $25 \%$ glucose solution was started at time zero and periodically adjusted to clamp the plasma glucose concentration at $\sim 6 \mathrm{mM}$. Plasma samples for determination of $\left[{ }^{3} \mathrm{H}\right]$ glucose- and $\left[{ }^{3} \mathrm{H}\right]$ water-specific activities $(\sim 45 \mu \mathrm{l}$ blood each) were obtained at $-40,-20,-10$, and 0 min during the basal period and at 20,30, 40, 60, 70, 80, and 90 min during the clamp period. Steady state conditions for the plasma glucose concentration and specific activity were achieved within $40 \mathrm{~min}$ in both the basal and clamp periods of the studies (see Fig. 1). Plasma samples for determination of plasma insulin concentrations $(\sim 40 \mu \mathrm{l}$ blood each) were obtained at time $-30,0,40,60,75$, and 90 min during the study. Additional plasma samples for the determination of plasma glucose concentration $(\sim 20 \mu \mathrm{l})$ were obtained at -40 and $-20 \mathrm{~min}$, and at 10 -min intervals thereafter. Plasma samples $(\sim 25 \mu \mathrm{l})$ for determination of plasma $\left[\mathrm{U}-{ }^{14} \mathrm{C}\right]$-2-deoxyglucose-specific activity were obtained at $45,46,48,50,55,60,70,80$, and 90 min during the clamp studies. The total volume of blood withdrawn was $\sim 1.2 \mathrm{ml} / \mathrm{study}$; to prevent volume depletion and anemia, a solution $(1: 1 \mathrm{vol} / \mathrm{vol})$ of $\sim 1.2 \mathrm{ml}$ fresh blood $(\sim 0.6 \mathrm{ml}$ obtained by heart puncture from littermates of the test animals) and heparinized saline $(10 \mathrm{U} / \mathrm{ml})$ was infused at a rate of $7 \mu \mathrm{l} / \mathrm{min}$. Furthermore, after larger samples at time $0,40,60$, and $90 \mathrm{~min}$, red blood cells were resuspended in saline and immediately returned through the infusion catheter. All determinations were also performed on portal vein blood obtained at the end of the experiment. To minimize stress during the sampling procedures, all mice were accustomed to handling and tail sampling, were freely moving within a large cage, and were allowed sufficient time for post-surgical recovery ( $4 \mathrm{~d}$ or more). Blood samples were obtained every $10 \mathrm{~min}$ from a cut at the tip of the tail (42).

At the end of the in vivo studies, mice were anesthetized (pentobarbital $60 \mathrm{mg} / \mathrm{kg}$ body wt, i.v.), the abdomen was quickly opened, portal vein blood was obtained, and abdominal and hindlimb muscle and liver were freeze-clamped in situ with aluminum tongs precooled in liquid nitrogen. The time from the injection of the anesthetic until freeze clamping of the tissues was $<45 \mathrm{~s}$. All tissue samples were stored at $-80^{\circ} \mathrm{C}$ for subsequent analysis.

The study protocol was reviewed and approved by the Institutional Animal Care and Use Committee of the Albert Einstein College of Medicine.

Analytical procedures. Plasma glucose was measured by the glucose oxidase method (Glucose Analyzer II; Beckman Instruments, Inc., Fullerton, CA). Plasma insulin was measured by radioimmunoassay, using rat and porcine insulin standards. Plasma $\left[{ }^{3} \mathrm{H}\right]$ glucose radioactivity was measured in duplicates in the supernatants of $\mathrm{Ba}(\mathrm{OH})_{2}$ and $\mathrm{ZnSO}_{4}$ precipitates (Somogyi procedure) of plasma samples $(20 \mu l)$ after evaporation to dryness to eliminate tritiated water. The rates of glycolysis were estimated as previously described (8, 42). Briefly, plasma-tritiated water-specific activity was determined by liquid scintillation counting of the protein-free supernatant (Somogyi filtrate) before and after evaporation to dryness. Because tritium on the $\mathrm{C}-3$ position of glucose is lost to water during glycolysis, it can be assumed that plasma tritium is present either in tritiated water or $\left[3-{ }^{3} \mathrm{H}\right]$ glucose. To measure plasma $\left[\mathrm{U}_{-14}{ }^{14} \mathrm{C}\right]-2$-deoxyglucose, samples were deproteinized as described above and an aliquot of the supernatant was counted in a double channel beta counter after addition of $500 \mu \mathrm{l}$ water and $5 \mathrm{ml}$ liquid scintillation cocktail. To measure muscle $\left[\mathrm{U}-{ }^{14} \mathrm{C}\right]-2$-deoxyglucose, frozen tissue samples were weighed and dissolved in $0.5 \mathrm{ml}$ of $1 \mathrm{M} \mathrm{NaOH}$ kept in a shaking water bath at $60^{\circ} \mathrm{C}$ for $1 \mathrm{~h}$. After neutralization with $0.5 \mathrm{ml}$ of $1 \mathrm{M} \mathrm{HCl}$, two aliquots were taken. One was deproteinized with $\mathrm{Ba}(\mathrm{OH})_{2}$ and $\mathrm{ZnSO}_{4}$ and the other with $6 \% \mathrm{HClO}_{4}$. The $\mathrm{HClO}_{4}$ supernatant contains both phosphorylated and unphosphorylated 2-deoxyglucose, whereas the $\mathrm{Ba}(\mathrm{OH})_{2}$ and $\mathrm{ZnSO}_{4}$ supernatant contains only the unphosphorylated form. The difference in disintegrations per minute between the two supernatants measures the muscle content of 2-deoxyglucosephosphate (46). Muscle glycogen concentration and glycogen synthase activity were determined as previously described $(10,45,47)$. Uridine diphospho-glucose (UDPGlc), UDPgalactose, and phosphoenolpyruvate (PEP) concentrations and specific activities in the liver were obtained through two sequential chromatographic separations, 
as previously reported $(36,42,45,48,49)$. GLUT4 protein content was assessed in striated muscle by Western blot analysis $(41,50,51)$. Total muscle membranes were subjected to $10 \%$ SDS-PAGE and transferred to nitrocellulose (MSI, Inc.,Westborough, MA). The gels were stained with Coomassie blue and the membranes with Ponseau S (Sigma Chemical Co.) to assess uniformity of loading and transfer. Blots were immunoreacted with a rabbit polyclonal antiserum prepared against the carboxy terminus of GLUT4 and visualized using the enhanced chemiluminescence reagent (Amersham Corp., Arlington Heights, IL) with goat anti-rabbit horseradish peroxidase-coupled IgG (Southern Biotechnology Associates, Birmingham, AL).

Calculations. Under steady state conditions for plasma glucose concentrations, the rate of glucose disappearance $(\mathrm{Rd})$ equals the rate of glucose appearance $(\mathrm{Ra})$. The latter was calculated as the ratio of the rate of infusion of $\left[3-{ }^{3} \mathrm{H}\right]$ glucose (disintegrations per minute) and the steady state plasma $\left[{ }^{3} \mathrm{H}\right]$ glucose-specific activity (disintegrations per minute per milligram). When exogenous glucose was given, the rate of endogenous glucose production was calculated as the difference between $\mathrm{Ra}$ and the infusion rate of glucose. The rate of 2-deoxyglucose uptake was calculated as described by Kraegen et al. (46). The percentage of the hepatic glucose-6-phosphate pool directly derived from plasma glucose was calculated as the ratio of $\left[{ }^{3} \mathrm{H}\right] \mathrm{UD}-$ PGlc- and plasma $\left[{ }^{3} \mathrm{H}\right]$ glucose-specific activities. The percentage of the hepatic glucose-6-phosphate pool derived from PEP-gluconeogenesis was calculated as the ratio of the specific activities of $\left[{ }^{14} \mathrm{C}\right]$ UDPGlc and $2 \times\left[{ }^{14} \mathrm{C}\right] \mathrm{PEP}$ after in vivo labeling with $\left[\mathrm{U}-{ }^{14} \mathrm{C}\right] \mathrm{lac}-$ tate $(42,45,49)$. Comparisons between groups were made with Student's $t$ test for unpaired samples.

\section{Results}

General characteristics of the experimental animals (Table I). To delineate the impact of a partial deficit in the expression of the insulin responsive facilitative glucose transporter, GLUT4, on whole body, skeletal muscle, and liver insulin action, six male mice with one GLUT4 allele disrupted by homologous recombination in mouse embryonic stem cells, GLUT4 (+/-), and eight male wild-type control mice, WT $(+/+)$, were studied. There were no differences in the mean body weights between the two groups of mice. After an $\sim 6 \mathrm{~h}$ fast (postabsorptive state), the plasma insulin concentration was significantly $(\sim 50 \%)$ higher in the GLUT4 $(+/-)$ than in the WT $(+/+)$ mice. Perhaps as a result of postabsorptive hyperinsulinemia, the basal rate of hepatic glucose production $(P=0.046)$ and the plasma glucose concentration $(P=0.087)$ were modestly decreased in the GLUT4 (+/-) compared with the WT $(+/+)$

Table I. General Characteristics of WT (+/+) and GLUT4 $(+/-)$ Mice Receiving the Hyperinsulinemic Clamp Studies

\begin{tabular}{lcc}
\hline \multicolumn{1}{c}{ Group } & WT $(+/+)$ & GLUT4 $(+/-)$ \\
\hline$n$ & 8 & 6 \\
Body wt $(\mathrm{g})$ & $37.9 \pm 1.2$ & $37.0 \pm 1.8$ \\
Plasma glucose $(\mathrm{mM})$ & $5.8 \pm 0.5$ & $5.1 \pm 0.4$ \\
Plasma insulin $(\mathrm{ng} / \mathrm{ml})$ & $2.1 \pm 0.3$ & $3.2 \pm 0.5^{*}$ \\
HGP $(\mathrm{mg} /$ kg per min) & $22.3 \pm 1.3$ & $18.1 \pm 1.9^{*}$
\end{tabular}

Mice were fasted for $6-8 \mathrm{~h}$ before plasma sampling. Biochemical parameters represent the average \pm SEM of at least three basal measurements in each mouse. HGP was calculated under steady state conditions between 60 and $80 \mathrm{~min}$ (average of four plasma samples) after starting the infusion of $\left[3-{ }^{3} \mathrm{H}\right]$ glucose. ${ }^{*} P<0.05$.
Table II. Steady State Plasma Glucose and Insulin Concentrations in WT (+/+) and GLUT4 (+/-) Mice during the Hyperinsulinemic Clamp Studies

\begin{tabular}{ccc}
\hline Group & WT $(+/+)$ & GLUT4 $(+/-)$ \\
\hline Glucose $(\mathrm{mM})$ & $6.4 \pm 0.3$ & $6.0 \pm 0.3$ \\
Insulin $(\mathrm{ng} / \mathrm{ml})$ & $52 \pm 8$ & $54 \pm 7$ \\
\hline
\end{tabular}

mice. Fed plasma glucose concentrations (not shown) were similar in the two groups.

Euglycemic hyperinsulinemic clamp studies (Table II and Fig. 1). To assess the metabolic effects of insulin in vivo, a similar increase in the plasma insulin concentrations was generated and the plasma glucose concentrations were maintained at $\sim 6 \mathrm{mM}$ by a variable glucose infusion. Thus, conscious mice were compared in the presence of similar steady state hyperinsulinemia and normoglycemia (Table II). Steady state conditions for plasma glucose-specific activity were achieved within 40 min during both the basal and clamp periods (Fig. 1, top). Similarly, the rate of accumulation of ${ }^{3} \mathrm{H}$-water in the plasma compartment, which reflects its generation from [3${ }^{3} \mathrm{H}$ ]glucose and is used in the calculation of the rate of glycolysis, was linear during the last $50 \mathrm{~min}$ of the basal and clamp periods (Fig. 1, bottom).

Effect of hyperinsulinemia on glucose disposal and on the partitioning of glucose fluxes (Figs. 2 and 3). The effect of a similar increase in the circulating insulin concentrations on the rates of tissue glucose uptake ( $\mathrm{Rd}$ ) and of glucose infusion is displayed in Fig. 2. All measurements were performed during the final $50 \mathrm{~min}$ of the clamp study, a time when steady state conditions were achieved for plasma glucose and insulin con-

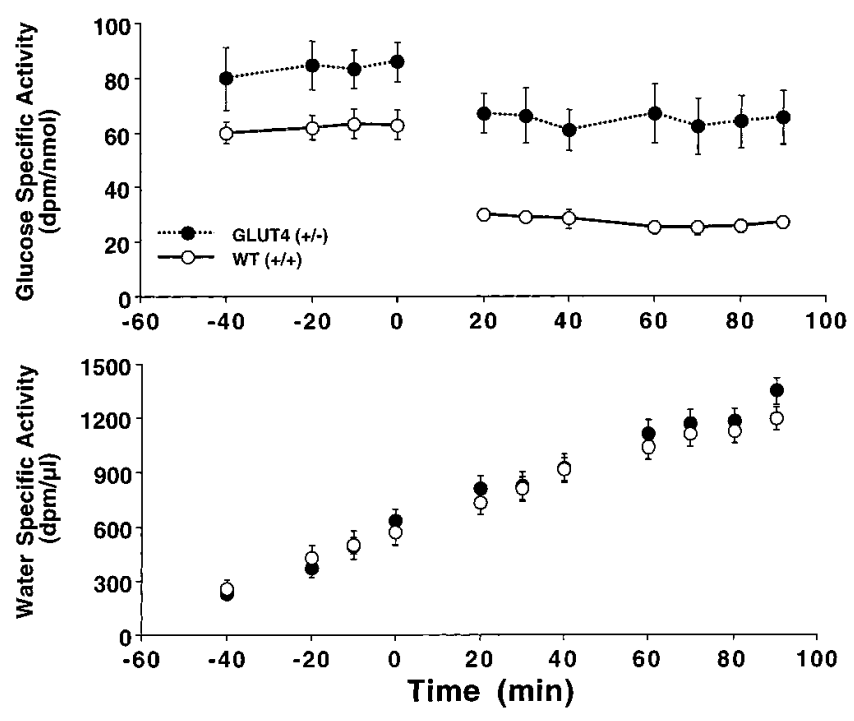

Figure 1. Time course of specific activities of plasma tritiated glucose (top) and water (bottom) during the basal period and the euglycemichyperinsulinemic clamp studies in GLUT4 $(+/-)$ and WT $(+/+)$ mice. Steady state conditions for glucose-specific activity were achieved during the last $40 \mathrm{~min}$ of the basal period and during the last $50 \mathrm{~min}$ of the clamp study. Similarly, the linear regression coefficients for the time courses of water-specific activity were $>0.9$ during the basal and clamp periods in all studies. 
A
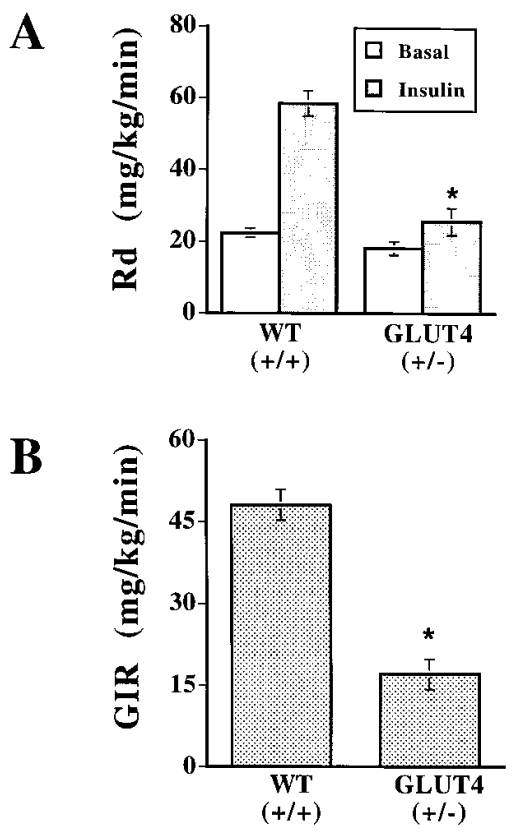

Figure 2. Effect of hyperinsulinemia on the rate of glucose disappearance $(A)$ and on the rate of glucose infusion $(B)$ in WT $(+/+)$ and GLUT4 $(+/-)$ mice. $(A) \mathrm{Rd}$ was measured by the tracer dilution technique during the basal period (Basal) and the euglycemichyperinsulinemic clamp studies (Insulin) in GLUT4 $(+/-)$ and WT $(+/+)$ mice. $(B)$ The rate of glucose infusion $(G I R)$ required to maintain the plasma glucose concentration at $\sim 6 \mathrm{mM}$ during the last $50 \mathrm{~min}$ of the euglycemic-hyperinsulinemic clamp studies was calculated in GLUT4 $(+/-)$ and WT $(+/+)$ mice. ${ }^{*} P<0.01$ vs. WT.

centrations, glucose-specific activity, and rates of glucose infusion. The rates of whole body glucose disappearance $[25.6 \pm 3.7$ and $58.4 \pm 3.6 \mathrm{mg} / \mathrm{kg}$ per min in GLUT4 $(+/-)$ and WT $(+/+)$, respectively; $P<0.001$; Fig. $2 A$ ] and of exogenous glucose infusion (Fig. $2 B$ ) required to maintain the target plasma glucose concentration during the hyperinsulinemic clamp study were decreased by 56 and $64 \%$, respectively, in GLUT4 (+/-) mice.

We next examined how this marked reduction in insulinmediated glucose uptake in mice with decreased GLUT4 expression affected the partitioning of glucose fluxes in the two major pathways of glucose disposal, glycogen synthesis, and glycolysis. As shown in Fig. 3, the rates of glycogen synthesis $(10.4 \pm 4.1$ vs. $24.7 \pm 3.0 ; P<0.01)$ and glycolysis $(15.8 \pm 1.2$ vs. $33.7 \pm 3.4 \mathrm{mg} / \mathrm{kg}$ per min; $P<0.01)$ during the hyperinsulinemic clamp studies were markedly reduced in GLUT4 $(+/-)$ compared with WT $(+/+)$ mice. Thus, the decreased rate of glucose uptake in GLUT4 (+/-) mice was accounted for by similar decreases $(\sim 56 \%)$ in the fluxes through glycogen syn-

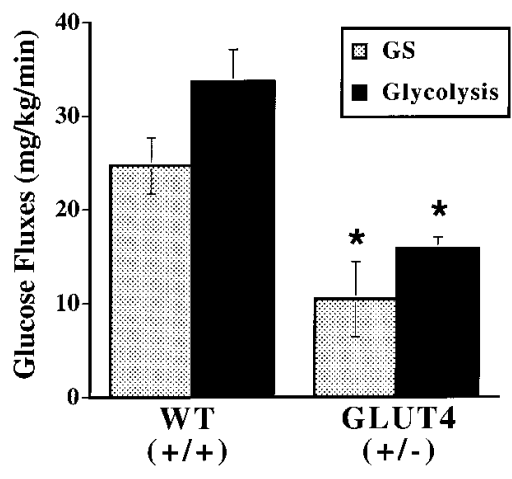

Figure 3. Effect of hyperinsulinemia on the rates of glycogen synthesis $(G S)$ and glycolysis during the euglycemichyperinsulinemic clamp studies in WT $(+/+)$ and GLUT4 $(+/-)$ mice. The decreased $\mathrm{Rd}$ in GLUT4 (+/-) mice was due to similar $(\sim 56 \%)$ decreases in the rates of GS and Glycolysis. $* P<0.01$ vs. WT $(+/+)$.

Table III. Activity of Glycogen Synthase and Concentration of Glycogen in Skeletal Muscle of WT (+/+) and GLUT4 (+/-) Mice at the End of the Hyperinsulinemic Clamp Studies

\begin{tabular}{ccc}
\hline Group & WT $(+/+)$ & GLUT4 $(+/-)$ \\
\hline Glycogen synthase $\left(\mathrm{FV}_{0.1}\right)$ & $32.5 \pm 3.0$ & $33.0 \pm 4.2$ \\
Glycogen content $(\mathrm{mg} \%)$ & $1180 \pm 23$ & $891 \pm 67^{*}$ \\
\hline
\end{tabular}

$* P<0.05$ vs. WT $(+/+)$.

thesis and glycolysis. Since under euglycemic hyperinsulinemic conditions the metabolism of glucose in striated muscle accounts for $>80 \%$ of glucose disposal, key biochemical parameters were next assessed in hindlimb muscle sampled at the completion of the in vivo studies.

Effect of genotype on muscle GLUT4 protein levels, deoxyglucose transport, and glycogen synthase (Table III; Fig. 4). Representative Western blot analyses and quantitation of GLUT4 protein levels in GLUT4 (+/-) and WT $(+/+)$ are
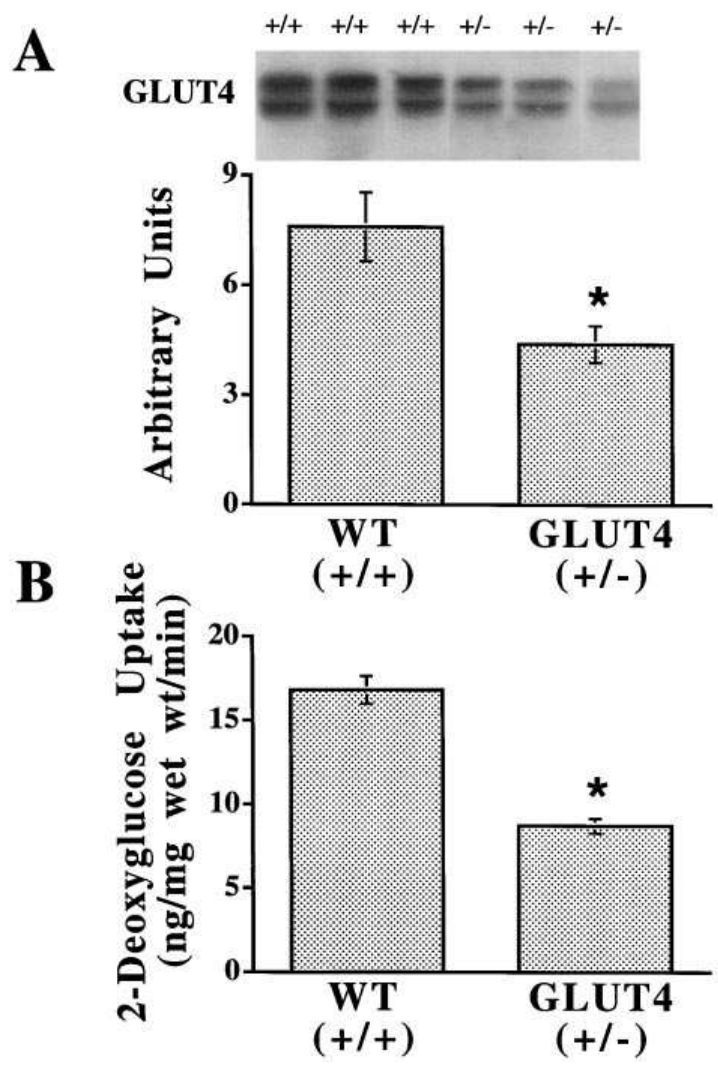

Figure 4. Quantification of GLUT4 protein by immunoblot analysis $(A)$ and rates of 2-deoxyglucose uptake in skeletal muscle $(B)$ of GLUT4 $(+/-)$ and WT $(+/+)$ mice at the end of the euglycemichyperinsulinemic clamp studies. $(A)$ The GLUT4 content was assessed by immunoblot analysis using an antisera specific for the carboxy terminus of GLUT4. Representative immunoblots from three GLUT4 (+/-) and three WT $(+/+)$ mice are shown in $A$, top, and graphs presenting the mean \pm SEM of arbitrary densitometric units derived from all experimental animals are shown below. $(B)$ The rate of skeletal muscle 2-deoxyglucose uptake during the last $45 \mathrm{~min}$ of the euglycemic-hyperinsulinemic clamp studies is displayed in $B$. $* P<0.01$ vs. WT. 
Table IV. Specific Activities of Hepatic Substrates Used to Calculate the "Direct Pathway" and the "Indirect Pathway" at the End of the $\left[3-{ }^{3} \mathrm{H}\right] \mathrm{Glucose}-\left[\mathrm{U}-{ }^{14} \mathrm{C}\right]$ Lactate Infusions of $W T(+/+)$ and GLUT4 (+/-) Mice

\begin{tabular}{lccccc}
\hline \multicolumn{1}{c}{ Group } & {$\left[{ }^{3} \mathrm{H}\right] \mathrm{Glc}$} & $\begin{array}{c}\left.{ }^{3} \mathrm{H}\right]- \\
\text { UDPGlc }\end{array}$ & $\begin{array}{c}\left.{ }^{[3} \mathrm{H}\right]- \\
\text { UDPGal }\end{array}$ & Glc & Gal \\
\hline & & $d p m / n m o l$ & & & percent \\
Direct & & & & & \\
$\quad$ WT $(+/+)$ & $28.1 \pm 0.7$ & $6.6 \pm 0.5$ & $6.6 \pm 0.4$ & $25.8 \pm 1.1$ & $26.1 \pm 1.3$ \\
$\quad$ GLUT4 (+/-) & $18.6 \pm 0.4$ & $6.4 \pm 1.1$ & $6.8 \pm 1.2$ & $23.8 \pm 3.2$ & $24.0 \pm 2.9$ \\
Indirect & & & & & \\
WT (+/+) & $41.9 \pm 3.9$ & $32.8 \pm 4.2$ & $31.0 \pm 3.7$ & $38.9 \pm 3.3$ & $38.3 \pm 4.1$ \\
GLUT4 (+/-) & $30.2 \pm 4.6$ & $23.0 \pm 3.4$ & $21.7 \pm 3.8$ & $42.0 \pm 6.5$ & $41.7 \pm 5.8$ \\
& & & & &
\end{tabular}

Abbreviations: Glc, plasma glucose; DIRECT, percentage of the hepatic Glc-6-P pool derived from plasma glucose, calculated as the ratio of the specific activities of [ $\left.{ }^{3} \mathrm{H}\right] \mathrm{UDPGlc}(\mathrm{Glc})$ or $\left[{ }^{3} \mathrm{H}\right] \mathrm{UDPGal}(\mathrm{Gal})$ and $\left[{ }^{3} \mathrm{H}\right] \mathrm{Glc}$; INDIRECT, percentage of the hepatic Glc-6-P pool derived from PEP-gluconeogenesis, calculated as the ratio of the specific activities of $\left[{ }^{14} \mathrm{C}\right]$ UDPGlc $(\mathrm{Glc})$ or $\left[{ }^{14} \mathrm{C}\right]$ UDPGal $(\mathrm{Gal})$ and $2 \times\left[{ }^{14} \mathrm{C}\right] \mathrm{PEP}$.

displayed in Fig. $4 A$. The disruption of a GLUT4 allele resulted in an $\sim 45 \%$ decrease in the GLUT4 protein levels in skeletal muscle. The rate of skeletal muscle glucose uptake during the last $45 \mathrm{~min}$ of the hyperinsulinemic clamp studies was measured using ${ }^{14} \mathrm{C}$-labeled 2 -deoxyglucose. The rate of muscle 2-deoxyglucose transport was markedly decreased $(\sim 65 \%)$ in the GLUT4 $(+/-)$ compared with the WT $(+/+)$ group. Taking into account the contribution of skeletal muscle to whole body glucose uptake under the conditions of hyperinsulinemic clamp studies, the latter result indicates that decreased uptake of glucose in skeletal muscle is largely responsible for peripheral insulin resistance.

A marked decrease in the rate of glycogen synthesis was also observed in GLUT4 $(+/-)$ mice. This impairment in the ability of insulin to stimulate the repletion of muscle glycogen was supported by the tracer-derived flux data (above) and by the significant decrease in muscle glycogen content at the completion of the clamp studies (Table III). However, this defect in muscle insulin action did not involve a diminished activation of glycogen synthase activity by insulin (Table III) and it was likely a direct consequence of the decreased rate of glucose transport and phosphorylation.

Effect of decreased GLUT4 gene expression on hepatic glucose fluxes (Table IV; Figs. 5 and 6). Fig. 5 depicts the rate of hepatic glucose production (HGP) during the basal period and its suppression by hyperinsulinemia. Basal HGP was slightly lower in the GLUT4 $(+/-)$ than in the WT $(+/+)$ mice. However, the inhibition of HGP during the hyperinsulinemic clamp studies was similar in the GLUT4 $(+/-)$ compared with the WT $(+/+)$ mice. In fact, the percent decrease in HGP from their basal values was 53 and 54\% in GLUT4 $(+/-)$ and WT $(+/+)$, respectively. Furthermore, the residual HGP during the clamp studies was similar in the two groups $(8.5 \pm 1.5$ and $10.3 \pm 2.1$ in GLUT4 $(+/-)$ and WT $(+/+)$, respectively; $P=$ 0.27 ). Thus, a primary defect in peripheral glucose disposal did not affect the ability of insulin to inhibit HGP.

However, it may be argued that alterations in GLUT4 abundance may result in more subtle changes in the partition-

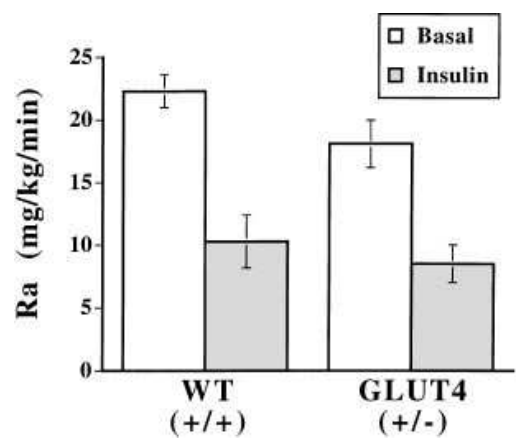

Figure 5. Effect of hyperinsulinemia on the rate of glucose appearance $(R a)$ in WT $(+/+)$ and GLUT4 $(+/-)$ mice. Rates of glucose appearance were assessed under steady state conditions during the basal period (Basal) and during the euglycemic-hyperinsulinemic clamp studies (Insulin). Measurements were performed during the last $40 \mathrm{~min}$ of the basal period and during the last $50 \mathrm{~min}$ of the clamp studies.

ing of liver glucose fluxes. In fact, an increased contribution of gluconeogenesis to HGP has been previously reported in animal models with increased insulin-mediated glucose disposal (35, 36). Thus, we next examined whether decreased GLUT4 expression altered the relative contribution of plasma glucose, gluconeogenesis, and glycogenolysis to the hepatic glucose-6-phosphate pool. Table IV displays the $\left[{ }^{3} \mathrm{H}\right]$ UDPglucose-, $\left[{ }^{3} \mathrm{H}\right] \mathrm{UDP}$ galactose-, and $\left[{ }^{3} \mathrm{H}\right]$ glucose-specific activities that are used to calculate the contribution of plasma glucose (Direct in Table IV) to the hepatic glucose-6-phosphate pool. The UDPgalactose-specific activities confirmed the values obtained with UDPglucose, suggesting rapid and complete isotopic equilibration between the two intracellular pools. The ratio of the specific activities of $\left[{ }^{3} \mathrm{H}\right]$ hepatic UDPglucose/galactose and portal vein plasma glucose provided an estimate of the contribution of the direct pathway. As shown in Table IV, the contributions of the direct pathway to the hepatic UDP hexose pool measured at the end of the clamp studies were similar in the GLUT4 $(+/-)$ compared with the WT $(+/+)$ mice.

Table IV also displays the $\left[{ }^{14} \mathrm{C}\right]$ UDPglucose-, $\left[{ }^{14} \mathrm{C}\right] \mathrm{UDPga}-$ lactose-, and $\left[{ }^{14} \mathrm{C}\right] \mathrm{PEP}$-specific activities that are used to calculate the contribution of PEP-gluconeogenesis (Indirect in Ta-

A

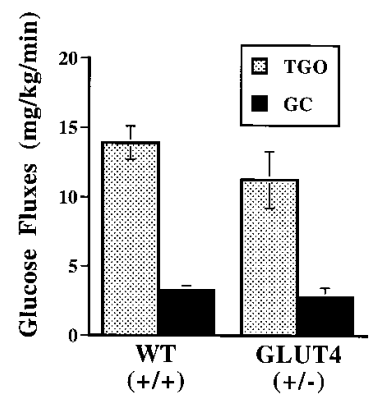

Figure 6. Rates of hepatic glucose fluxes in WT $(+/+)$ and GLUT4

B

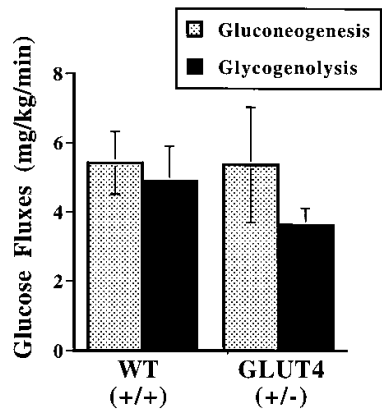

$(+/-)$ mice. $(A)$ Rates of total glucose output $(T G O)$ and of glucose cycling $(G C)$ during the euglycemic-hyperinsulinemic clamp studies are displayed. (B) Rates of gluconeogenesis and hepatic glycogenolysis during the euglycemichyperinsulinemic clamp studies are displayed. 
ble IV) to the hepatic glucose-6-phosphate pool. The indirect pathway accounted for $\sim 40 \%$ of the hepatic UDPglucose pool in both groups. These data allowed us to estimate the in vivo fluxes through glucose-6-phosphatase and the rates of glucose cycling, gluconeogenesis, and glycogenolysis in GLUT4 (+/-) and WT $(+/+)$ mice. As shown in Fig. 6, the contributions of glucose cycling and gluconeogenesis to total glucose output were unchanged in the GLUT4 $(+/-)$ mice compared with the WT $(+/+)$ mice. The modest decrease in the rate of glycogenolysis in the GLUT4 (+/-) group did not achieve statistical significance and was probably a reflection of the similar decrease in HGP during both the basal and clamp periods. Thus, a primary deficit in the level of expression of the insulinresponsive glucose transporter, GLUT4, can lead to peripheral insulin resistance in the absence of any detectable alterations in insulin action on hepatic glucose fluxes.

\section{Discussion}

Targeted disruption of one allele of the GLUT4 gene was achieved by homologous recombination using embryonic stem cell technology (41). This approach generated a unique animal model in which whole body and tissue-specific effects of a primary and partial defect in the level of expression of this facilitative glucose transporter protein could be delineated. Although defective insulin stimulation of glucose transport in skeletal muscle is commonly believed to represent the rate-determining defect in most insulin resistant states $(4,7,9,13,14,52)$, this abnormality occurs in the context of several concomitant alterations in the actions of insulin on glucose storage and oxidation and on hepatic glucose metabolism $(23,25,26,28,29)$. It is therefore fundamental to isolate the metabolic profile of a primary and physiologically relevant alteration in the level of GLUT4 gene expression.

To this end, we assessed the in vivo action of insulin on whole body, hepatic, and skeletal muscle glucose fluxes using the euglycemic hyperinsulinemic clamp technique in conscious GLUT4 $(+/-)$ and WT $(+/+)$ mice. Some comments are warranted regarding the selection of our experimental model. As previously reported (41), GLUT4 (-/-) null mice display multiple and severe abnormalities, which include growth retardation, decreased longevity, depletion of fat deposits, and cardiac changes. The metabolic characterization of GLUT4 $(-/-)$ mice has revealed the presence of marked hyperinsulinemia and skeletal muscle insulin resistance (51). However, mild hyperglycemia was present only in male GLUT4 null mice. Furthermore, insulin-stimulated glucose uptake was decreased but not abolished in isolated soleus muscle of female GLUT4 null mice $(41,51)$.

While the study of GLUT4 null mice has unveiled the dramatic consequences of a complete lack of expression of this gene product on an array of organ systems, a structural defect in the GLUT4 gene has not been observed in humans $(4,16$, 17, 21). The GLUT4 (+/-) mouse appears to reflect more accurately the human conditions. Indeed, a high degree of spontaneous variability in the level of GLUT4 protein has been reported in human skeletal muscle $(4,16,18,19,21)$ and, in subjects with normal glucose tolerance, a strong correlation has been demonstrated between basal levels of expression of GLUT4 in skeletal muscle and the rate of insulin-mediated glucose disposal during euglycemic clamp studies $(16,19)$. Thus, a primary objective of the present study was to delineate whether the induction of a physiologically relevant decrease in GLUT4 protein expression would be sufficient to account for whole body and skeletal muscle insulin resistance. However, while GLUT4 abundance per se could play a major role in determining interindividual variations in peripheral insulin action $(16,19,22)$, it is clear that once diabetes mellitus and/or obesity are present, other mechanisms are likely to participate in the pathophysiology of insulin resistance $(4,16,18,21,26)$. For example, decreased translocation of GLUT4 to the plasmalemma and to the $T$ tubules in response to insulin can be induced by chronic hyperglycemia $(4,5,44,53-55)$ and/or hyperlipidemia $(56,57)$. Thus, in the attempt to isolate the direct consequences of a primary and moderate reduction in GLUT4 protein expression on in vivo insulin action, we studied 4-5-mo-old GLUT4 (+/-) mice that were normoglycemic and presented normal growth and body composition.

A fundamental premise of our experimental design was that the genetic manipulations implemented in this animal model resulted in decreased GLUT4 protein abundance in the tissue responsible for the great majority of insulin-mediated glucose disposal; i.e., skeletal muscle. Indeed, GLUT4 (+/-) mice displayed a consistent $\sim 45 \%$ decrease in GLUT4 protein levels in skeletal muscle (Fig. $4 \mathrm{~A}$ ). The extent of this deficit in GLUT4 expression induced by the disruption of one allele of the GLUT4 gene suggests that compensatory mechanisms are not activated in skeletal muscle of GLUT4 $(+/-)$ mice. Thus, this animal model allowed us to investigate whether a primary and partial deficit in the level of GLUT4 expression would alter the in vivo action of insulin on $(a)$ whole body and skeletal muscle glucose uptake, $(b)$ partitioning of intracellular glucose disposal, and/or $(c)$ hepatic glucose fluxes.

Is a decreased level of GLUT4 expression sufficient to induce severe peripheral insulin resistance? While a modest decrease in postabsorptive HGP was present in the GLUT4 $(+/-)$ compared with the WT $(+/+)$ mice, the basal rate of glucose clearance was not significantly diminished. The latter observation appears to confirm the relatively minor role that GLUT4 plays in basal glucose homeostasis (4). However, it should also be pointed out that basal glucose kinetics were assessed in the presence of significantly higher plasma insulin concentrations in the GLUT4 $(+/-)$ than in the WT $(+/+)$ mice. Thus, the observed rates of HGP may be consistent with the differences in the circulating plasma insulin levels and the normalcy of the rate of glucose clearance in GLUT4 (+/-) mice may be due to the presence of relative postabsorptive hyperinsulinemia in this group. However, it is quite clear that, during the hyperinsulinemic clamp studies, the ability of hyperinsulinemia to promote glucose disposal was markedly diminished in the GLUT4 $(+/-)$ compared with the WT $(+/+)$ mice. This was reflected in $\sim 60 \%$ decreases in the rates of glucose infusion, tissue glucose uptake (Rd), and skeletal muscle deoxyglucose transport during the insulin clamp studies. Thus, an $\sim 45 \%$ decrease in the abundance of GLUT4 protein in skeletal muscle leads to severe peripheral insulin resistance.

Several recent studies have reported the metabolic impact of marked increases in the level of gene expression of either GLUT1 or GLUT4 in transgenic mice $(7,35,50,52,58-63)$. These studies have consistently shown that, when muscle or adipose tissue glucose transport was enhanced, glucose tolerance was improved and basal rates of glucose disposal were increased. However, insulin-stimulated glucose disposal was markedly increased in GLUT4 transgenic mice $(35,50,60-63)$ 
and impaired in GLUT1 transgenic mice $(52,58)$. Taken together, GLUT1 and GLUT4 transgenic models have also elegantly demonstrated the therapeutic potential of any intervention designed to stimulate the gene expression of these glucose transporters (64). The rate-limiting role of glucose transport in insulin-mediated glucose disposal under most physiologic conditions and its pivotal role in the insulin resistance of NIDDM is also supported by kinetic forearm $(14,15)$ and by ${ }^{31} \mathrm{P}$ nuclear magnetic resonance $(9,12)$ studies. However, it should be pointed out that the demonstration of severe resistance to the stimulatory effect of insulin on peripheral glucose uptake in the presence of a selective and primary reduction in GLUT4 protein is the most direct proof to date of the rate-limiting role of glucose transport in whole body and skeletal muscle insulinmediated glucose uptake. Furthermore, these findings support the notion that spontaneous variations in the level of GLUT4 gene expression in human skeletal muscle are likely to be a major determinant of the peripheral sensitivity to insulin.

Does a primary defect in insulin-mediated glucose transport alter the intracellular pathways of glucose use? After transport and phosphorylation, glucose is metabolized in two major intracellular pathways, glycolysis and glycogen synthesis. While in NIDDM, defects have been demonstrated in insulin stimulation of glucose uptake, storage, and oxidation (23-26, 28-31), it remains controversial whether the decreased rate of glucose uptake can be solely responsible for the impaired intracellular use of glucose $(24,65)$. In young siblings of one or two NIDDM parents, a population at high risk to develop NIDDM later in life, peripheral insulin resistance has been reported $(12,25,30)$. Most important, the decreased rate of glucose disposal during insulin clamp studies in these "prediabetic" subjects was almost entirely accounted for by a marked reduction in the rate of nonoxidative glucose disposal (30), largely reflecting glycogen synthesis in skeletal muscle $(30,31)$. Defective activation of skeletal muscle glycogen synthase by insulin has also been reported in these high risk populations (30).

Thus, it was important to delineate whether a primary defect in glucose transport, leading to a chronic decrease in insulin-mediated glucose uptake, would preferentially alter one of the pathways of intracellular glucose disposal and/or impair the stimulation of glycogen synthase activity by insulin. To address this question, we measured the disposal of glucose into the glycogenic and glycolytic pathways and the activity of glycogen synthase in skeletal muscle during the euglycemic clamp studies. The decreased rate of glucose disposal in the GLUT4 $(+/-)$ mice was accounted for by similar $\sim 56 \%$ decreases in both the rates of glycogen synthesis and glycolysis. Furthermore, the activity of glycogen synthase in skeletal muscle sampled at the completion of the in vivo studies was similar in the GLUT4 (+/-) and WT $(+/+)$ mice. The marked decrease in the in vivo rates of glycogen synthesis and in the final concentration of skeletal muscle glycogen in the presence of normally activated glycogen synthase indicated that a primary defect in glucose transport is sufficient to limit glycogen repletion and that a chronic impairment in the action of insulin on glucose uptake does not lead to abnormal activity of glycogen synthase in muscle.

Does a primary defect in insulin-mediated peripheral glucose transport and use lead to hepatic insulin resistance and/or to an intrahepatic redistribution of glucose fluxes? In NIDDM and in most other insulin-resistant states, peripheral and hepatic insulin resistance coexist and appear to be tightly linked
(27). Increasing evidence has recently been provided in support of the notion that insulin inhibits HGP in large part via its effects on peripheral tissues $(32-34,66-68)$. Thus, it may be hypothesized that peripheral insulin resistance ultimately leads to hepatic insulin resistance. Conversely, recent work in transgenic mouse models indicated that a marked increase in the rate of peripheral glucose disposal markedly increased the rate of hepatic gluconeogenesis. Under basal conditions, this resulted in a significant increase in HGP; while in the presence of hyperinsulinemia an intrahepatic redistribution of hepatic glucose fluxes, with increased gluconeogenesis and decreased glycogenolysis, was observed $(35,36)$.

In the present study, GLUT4 (+/-) mice displayed a complete dissociation between hepatic and peripheral insulin resistance. In fact, in the presence of a severe impairment in insulin-mediated glucose disposal, the ability of insulin to inhibit HGP was similar in GLUT4 $(+/-)$ and WT $(+/+)$ mice. Furthermore, decreased whole body glucose flux did not affect the relative contributions of the gluconeogenic and glycogenolytic pathways to the hepatic glucose-6-phosphate pool. Indeed, the contributions of glucose cycling, gluconeogenesis, and glycogenolysis to total glucose output were remarkably similar in the GLUT4 $(+/-)$ and WT $(+/+)$ mice. This apparent discrepancy regarding the metabolic consequences of decreased and increased rates of peripheral glucose disposal on hepatic glucose fluxes may be due to the saturating effects of major increases in the rates of glucose uptake on pyruvate dehydrogenase. This would result in a major increase in the rate of anaerobic glycolysis in the presence of increased peripheral glucose disposal, but minimal changes in this parameter when glucose uptake is decreased.

Finally, it should be pointed out that GLUT4 (+/-) mice do not display significant changes in the plasma FFA concentrations that have been postulated to be the major link between the peripheral and hepatic actions of insulin $(66,68,69)$. Regardless of the metabolic and/or endocrine mechanisms that may link the peripheral and hepatic actions of insulin under normal conditions, our findings indicate that a primary defect in peripheral insulin action on glucose transport does not lead to the onset of hepatic insulin resistance nor to changes in the contribution of gluconeogenesis to HGP.

In conclusion, disruption of an allele of the GLUT4 gene in mice leads to severe peripheral insulin resistance with parallel and similar decreases in glucose storage into glycogen and glycolysis. However, this primary defect in insulin-responsive glucose transport does not result in secondary defects in the activation of skeletal muscle glycogen synthase or in the regulation of hepatic glucose fluxes by insulin. We propose that genetic or acquired changes in the abundance of this glucose transporter protein in skeletal muscle can markedly alter whole body glucose homeostasis and are likely to account for interindividual variations in peripheral insulin sensitivity.

\section{Acknowledgments}

The authors thank Rong Liu and Robin Squeglia for their excellent technical assistance.

This work was supported by grants from the National Institutes of Health (NIH) (DK-45024 and DK-48321 to L. Rossetti and DK47425 to M.J. Charron), the Juvenile Diabetes Foundation, and by the Albert Einstein Diabetes Research and Training Center (DK20541). M.J. Charron is a Pew Scholar in Biomedical Sciences. N. 
Barzilai is the recipient of a Clinical Investigator Award from the NIH (KO8-AG00639). A.E. Stenbit was supported by a predoctoral fellowship from the NIH. L. Rossetti is the recipient of a Career Scientist Award from the Irma T. Hirschl Trust.

\section{References}

1. Birnbaum, M. 1989. Identification of a novel gene encoding an insulinresponsive glucose transporter protein. Cell. 57:305-315.

2. Charron, M., F.D. Brosius, S. Alper, and H. Lodish. 1989. A glucose transport protein expressed predominately in insulin-responsive tissues. Proc. Natl. Acad. Sci. USA. 86:2535-2539.

3. Mueckler, M. 1994. Facilitative glucose transporters. Eur. J. Biochem. 219:713-725.

4. Kahn, B. 1996. Lilly lecture 1995. Glucose transport: pivotal step in insulin action. Diabetes. 45:1644-1654.

5. Marette, A., E. Burdett, A. Douen, M. Vranic, and A. Klip. 1992. Insulin induces the translocation of GLUT4 from a unique intracellular organelle to transverse tubules in rat skeletal muscle. Diabetes. 41:1562-1569.

6. Wang, W., P. Hansen, B. Marshall, J. Holloszy, and M. Mueckler. 1996. Insulin unmasks a $\mathrm{COOH}$-terminal Glut4 epitope and increases glucose transport across T-tubules in skeletal muscle. J. Cell Biol. 135:415-430.

7. Ren, J., B. Marshall, E. Gulve, J. Gao, D. Johnson, J. Holloszy, and M. Mueckler. 1993. Evidence from transgenic mice that glucose transport is ratelimiting for glycogen deposition and glycolysis in skeletal muscle. J. Biol. Chem. 268:16113-16115.

8. Rossetti, L., and A. Giaccari. 1990. Relative contribution of glycogen synthesis and glycolysis to insulin-mediated glucose uptake. A dose-response euglycemic clamp study in normal and diabetic rats. J. Clin. Invest. 85:17851792 .

9. Rothman, D., R. Shulman, and G. Shulman. 1992. ${ }^{31} \mathrm{P}$ nuclear magnetic resonance measurements of muscle glucose-6-phosphate. J. Clin. Invest. 89: 1069-1075.

10. Rossetti, L., and M. Hu. 1993. Skeletal muscle glycogenolysis is more sensitive to insulin than is glucose transport/phosphorylation. Relation to the insulin-induced inhibition of hepatic glucose production. J. Clin. Invest. 92: 2963-2974.

11. Price, T., G. Perseghin, A. Duleba, W. Chen, J. Chase, D. Rothman, R. Shulman, and G. Shulman. 1996. NMR studies of muscle glycogen synthesis in insulin-resistant offspring of parents with non-insulin-dependent diabetes mellitus immediately after glycogen-depleting exercise. Proc. Natl. Acad. Sci. USA. 93:5329-5334

12. Rothman, D., I. Magnusson, G. Cline, D. Gerard, C. Kahn, R. Shulman, and G. Shulman. 1995. Decreased muscle glucose transport/phosphorylation is an early defect in the pathogenesis of non-insulin-dependent diabetes mellitus. Proc. Natl. Acad. Sci. USA. 92:983-987.

13. Butler, P., E. Kryshak, M. Marsh, and R. Rizza. 1990. Effect of insulin on oxidation of intracellularly and extracellularly derived glucose in patients with NIDDM. Evidence for primary defect in glucose transport and/or phosphorylation but not oxidation. Diabetes. 39:1373-1380.

14. Bonadonna, R., S. Del Prato, M. Saccomani, E. Bonora, G. Gulli, E. Ferrannini, D. Bier, C. Cobelli, and R. DeFronzo. 1993. Transmembrane glucose transport in skeletal muscle of patients with non-insulin-dependent diabetes. J. Clin. Invest. 92:486-494.

15. Bonadonna, R., S. Del Prato, E. Bonora, M. Saccomani, G. Gulli, A. Natali, S. Frascerra, N. Pecori, E. Ferrannini, D. Bier, et al. 1996. Roles of glucose transport and glucose phosphorylation in muscle insulin resistance of NIDDM. Diabetes. 45:915-925.

16. Eriksson, J., L. Koranyi, R. Bourey, C. Schalin-Jantti, E. Widen, M. Mueckler, A.M. Permutt, and L.C. Groop. 1994. Insulin resistance in Type 2 (non-insulin-dependent) diabetic patients and their relatives is not associated with a defect in the expression of the insulin-responsive glucose transporter (GLUT-4) gene in human skeletal muscle. Diabetologia. 35:143-147.

17. Kusari, J., U. Verma, J. Buse, R. Henry, and J. Olefsky. 1991. Analysis of the gene sequences of the insulin receptor and the insulin-sensitive glucose transporter (GLUT-4) in patients with common-type non-insulin-dependent diabetes mellitus. J. Clin. Invest. 88:1323-1330.

18. Andersen, P., S. Lund, H. Vestergaard, S. Junker, B. Kahn, and O. Pedersen. 1993. Expression of the major insulin regulatable glucose transporter (GLUT4) in skeletal muscle of non-insulin-dependent diabetic patients and healthy subjects before and after insulin infusion. J. Clin. Endocrinol. Metab. 77:27-32.

19. Koranyi, L., R. Bourey, H. Vuorinen-Markkola, V. Koivisto, M. Mueckler, M. Permutt, and H. Yki-Jarvinen. 1991. Level of skeletal muscle glucose transporter protein correlates with insulin-stimulated whole body glucose disposal in man. Diabetologia. 34:763-765.

20. Schalin-Jantti, C., H. Yki-Jarvinen, L. Koranyi, R. Bourey, J. Lindstrom, P. Nikula-Ijas, A. Franssila-Kallunki, and L. Groop. 1994. Effect of insulin on GLUT-4 mRNA and protein concentrations in skeletal muscle of patients with NIDDM and their first-degree relatives. Diabetologia. 37:401-407.
21. Pedersen, O., J. Bak, P. Andersen, S. Lund, D. Moller, J. Flier, and B. Kahn. 1990. Evidence against altered expression of GLUT1 or GLUT4 in skeletal muscle of patients with obesity or NIDDM. Diabetes. 39:865-870.

22. Hollenbeck, C., and G. Reaven. 1987. Variations in insulin-stimulated glucose uptake in healthy individuals with normal glucose tolerance. J. Clin. Endocrinol. Metab. 64:1169-1173.

23. Thorburn, A., B. Gumbiner, F. Bulacan, G. Brechtel, and R. Henry. 1991. Multiple defects in muscle glycogen synthase activity contribute to reduced glycogen synthesis in non-insulin-dependent diabetes mellitus. J. Clin. Invest. 87:489-495.

24. Thorburn, A., B. Gumbiner, F. Bulacan, P. Wallace, and R. Henry. 1990. Intracellular glucose oxidation and glycogen synthase activity are reduced in non-insulin-dependent (type II) diabetes independent of impaired glucose uptake. J. Clin. Invest. 85:522-529.

25. Gulli, G., E. Ferrannini, M. Stern, S. Haffner, and R. DeFronzo. 1992. The metabolic profile of NIDDM is fully established in glucose-tolerant offspring of two Mexican-American NIDDM parents. Diabetes. 41:1575-1586.

26. Groop, L., R. Bonadonna, S. DelPrato, K. Ratheiser, K. Zyck, E. Ferrannini, and R. DeFronzo. 1989. Glucose and free fatty acid metabolism in non-insulin-dependent diabetes mellitus. Evidence for multiple sites of insulin resistance. J. Clin. Invest. 84:205-213.

27. Butler, P., E. Kryshak, W. Schwenk, M. Haymond, and R. Rizza. 1990. Hepatic and extrahepatic responses to insulin in NIDDM and nondiabetic humans. Assessment in absence of artifact introduced by tritiated nonglucose contaminants. Diabetes. 39:217-225.

28. Del Prato, S., R. Bonadonna, E. Bonora, G. Gulli, A. Solini, M. Shank, and R. DeFronzo. 1993. Characterization of cellular defects of insulin action in type 2 (non-insulin-dependent) diabetes mellitus. J. Clin. Invest. 91:484-494.

29. Vaag, A., F. Alford, F. Henriksen, M. Christopher, and H. BeckNielsen. 1995. Multiple defects of both hepatic and peripheral intracellular glucose processing contribute to the hyperglycaemia of NIDDM. Diabetologia. 38 326-336.

30. Vaag, A., J. Henriksen, and H. Beck-Nielsen. 1992. Decreased insulin activation of glycogen synthase in skeletal muscles in young nonobese Caucasian first-degree relatives of patients with non-insulin-dependent diabetes mellitus. J. Clin. Invest. 89:782-788.

31. Shulman, G.I., D.L. Rothman, T. Jue, P. Stein, R.A. DeFronzo, and R.G. Shulman. 1990. Quantitation of muscle glycogen synthesis in normal subjects and subjects with non-insulin-dependent diabetes by ${ }^{13} \mathrm{C}$ nuclear magnetic resonance spectroscopy. N. Engl. J. Med. 322:223-228.

32. Giacca, A., S. Fisher, Z. Shi, R. Gupta, H. Lickley, and M. Vranic. 1992. Importance of peripheral insulin levels for insulin-induced suppression of glucose production in depancreatized dogs. J. Clin. Invest. 90:1769-1777.

33. Bradley, D., R. Poulin, and R. Bergman. 1993. Dynamics of hepatic and peripheral insulin effects suggest common rate-limiting step in vivo. Diabetes. 42:296-306.

34. Lewis, G., B. Zinman, Y. Groenewoud, M. Vranic, and A. Giacca. 1996 Hepatic glucose production is regulated both by direct hepatic and extrahepatic effects of insulin in humans. Diabetes. 45:454-462.

35. Ren, J., B. Marshall, M. Mueckler, M. McCaleb, J. Amatruda, and G. Shulman. 1995. Overexpression of Glut 4 protein in muscle increases basal and insulin-stimulated whole body glucose disposal in conscious mice. J. Clin. Invest. 95:429-432.

36. Rossetti, L., N. Barzilai, W. Chen, T. Harris, D. Yang, and C.E. Rogler. 1996. Hepatic overexpression of insulin-like growth factor-II in adulthood increases basal and insulin-stimulated glucose disposal in conscious mice. J. Biol. Chem. 271:203-208.

37. Turk, D., A. Alzaid, S. Dinneen, K.S. Nair, and R. Rizza. 1995. The effects of non-insulin-dependent diabetes mellitus on the kinetics of onset of insulin action in hepatic and extrahepatic tissues. J. Clin. Invest. 95:755-762.

38. Vaag, A., J. Henriksen, S. Madsbad, N. Holm, and H. Beck-Nielsen. 1995. Insulin secretion, insulin action, and hepatic glucose production in identical twins discordant for non-insulin-dependent diabetes mellitus. J. Clin. Invest. 95:690-698.

39. Ferrannini, E., G. Buzzigoli, R. Bonadonna, M. Giorico, M. Oleggini, L. Graziadei, R. Pedrinelli, L. Brandi, and S. Bevilacqua. 1987. Insulin resistance in essential hypertension. N. Engl. J. Med. 317:350-357.

40. Bianchi, S., R. Bigazzi, A. Quinones-Galvan, E. Muscelli, G. Baldari, N. Pecori, D. Ciociaro, E. Ferrannini, and A. Natali. 1995. Insulin resistance in microalbuminuric hypertension. Sites and mechanisms. Hypertension (Dallas). 26: 789-795.

41. Katz, E., A. Stenbit, K. Hatton, R. DePinho, and M. Charron. 1995. Cardiac and adipose tissue abnormalities but not diabetes in mice deficient in GLUT4. Nature (Lond.). 377:151-155.

42. Massillon, D., W. Chen, M. Hawkins, R. Liu, N. Barzilai, and L. Rossetti. 1995. Quantitation of hepatic glucose fluxes and pathways of hepatic glycogen synthesis in conscious mice. Am. J. Physiol. 269:E1037-E1043.

43. Bali, D., A. Svetlanov, H.W. Lee, D. Fusco-DeMane, M. Leiser, B. Li, N. Barzilai, M. Surana, H. Hou, N. Fleischer, et al. 1995. Animal model for maturity-onset diabetes of the young generated by disruption of the mouse glucokinase gene. J. Biol. Chem. 270:21464-21467.

44. Rossetti, L., D. Smith, G.I. Shulman, D. Papachristou, and R.A. De- 
Fronzo. 1987. Correction of hyperglycemia with phlorizin normalizes tissue sensitivity to insulin in diabetic rats. J. Clin. Invest. 79:1510-1515.

45. Rossetti, L., A. Giaccari, N. Barzilai, K. Howard, G. Sebel, and M. Hu. 1993. Mechanism by which hyperglycemia inhibits hepatic glucose production in conscious rats. Implications for the pathophysiology of fasting hyperglycemia in diabetes. J. Clin. Invest. 92:1126-1134.

46. Kraegen, E., D. James, A. Jenkins, and P. Chisolm. 1985. Dose-response curves for in vivo insulin sensitivity for individual tissues in rats. Am. J. Physiol. 248:E353-E362.

47. Rossetti, L., and M. Laughlin. 1989. Correction of chronic hyperglycemia with vanadate, but not with phlorizin, normalizes in vivo glycogen repletion and in vitro glycogen synthase activity in diabetic skeletal muscle. J. Clin. Invest. 84:892-899.

48. Giaccari, A., and L. Rossetti. 1989. Isocratic high-performance liquid chromatographic determination of the concentration and specific radioactivity of phosphoenolpyruvate and uridine diphosphate glucose in tissue extracts. $J$. Chromatogr. 497:69-78.

49. Giaccari, A., and L. Rossetti. 1992. Predominant role of gluconeogenesis in the hepatic glycogen repletion of diabetic rats. J. Clin. Invest. 89:36-45.

50. Tsao, T., R. Burcelin, E. Katz, L. Huang, and M. Charron. 1996. Enhanced insulin action due to targeted GLUT4 overexpression exclusively in muscle. Diabetes. 45:28-36.

51. Stenbit, A.E., R. Burcelin, E. Katz, T. Tsao, N. Gautier, M. Charron, and Y. Le Marchand-Brustel. 1996. Diverse effects of Glut 4 ablation on glucose uptake and glycogen synthesis in red and white skeletal muscle. J. Clin. Invest. 98:629-634.

52. Marshall, B., J. Ren, D. Johnson, E. Gibbs, J. Lillquist, W. Soeller, J. Holloszy, and M. Mueckler. 1993. Germline manipulation of glucose homeostasis via alteration of glucose transporter levels in skeletal muscle. J. Biol. Chem. 268:18442-18445.

53. Kahn, B., L. Rossetti, H. Lodish, and M. Charron. 1991. Decreased in vivo glucose uptake but normal expression of GLUT1 and GLUT4 in skeletal muscle of diabetic rats. J. Clin. Invest. 87:2197-2206.

54. Kahn, B., G. Shulman, R. DeFronzo, S. Cushman, and L. Rossetti. 1991. Normalization of blood glucose in diabetic rats with phlorizin treatment reverses insulin-resistant glucose transport in adipose cells without restoring glucose transporter gene expression. J. Clin. Invest. 87:561-570.

55. Dimitrakoudis, D., T. Ramlal, S. Rastogi, M. Vranic, and A. Klip. 1992. Glycaemia regulates the glucose transporter number in the plasma membrane of rat skeletal muscle. Biochem. J. 284:341-348.

56. Roden, M., T. Price, G. Perseghin, K. Petersen, D. Rothman, G. Cline, and G. Shulman. 1996. Mechanism of free fatty acid-induced insulin resistance in humans. J. Clin. Invest. 97:2859-2865.

57. Zierath, J., K. Houseknecht, L. Gnudi, and B. Kahn. 1997. High-fat feeding impairs insulin-stimulated GLUT4 recruitment via an early insulin-signaling defect. Diabetes. 46:215-223.
58. Gulve, E., J. Ren, B. Marshall, J. Gao, P. Hansen, J. Holloszy, and M. Mueckler. 1994. Glucose transport activity in skeletal muscles from transgenic mice overexpressing GLUT1. Increased basal transport is associated with a defective response to diverse stimuli that activate GLUT4. J. Biol. Chem. 269: $17765-17767$.

59. Hansen, P., E. Gulve, B. Marshall, J. Gao, J. Pessin, J. Holloszy, and M. Mueckler. 1995. Skeletal muscle glucose transport and metabolism are enhanced in transgenic mice overexpressing the Glut4 glucose transporter. J. Biol. Chem. 270:1679-1684.

60. Leturque, A., M. Loizeau, S. Vaulont, M. Salminen, and J. Girard. 1996. Improvement of insulin action in diabetic transgenic mice selectively overexpressing GLUT4 in skeletal muscle. Diabetes. 45:23-27.

61. Liu, M., E. Gibbs, S. McCoid, A. Milici, H. Stukenbrok, R. McPherson, J. Treadway, and J. Pessin. 1993. Transgenic mice expressing the human GLUT4/muscle-fat facilitative glucose transporter protein exhibit efficient glycemic control. J. Biol. Chem. 268:22231-22234.

62. Treadway, J., D. Hargrove, N. Nardone, R. McPherson, J. Russo, A. Milici, H. Stukenbrok, E. Gibbs, R. Stevenson, and J. Pessin. 1994. Enhanced peripheral glucose utilization in transgenic mice expressing the human GLUT4 gene. J. Biol. Chem. 269:29956-29961.

63. Shepherd, P., L. Gnudi, E. Tozzo, H. Yang, F. Leach, and B. Kahn. 1993. Adipose cell hyperplasia and enhanced glucose disposal in transgenic mice overexpressing GLUT4 selectively in adipose tissue. J. Biol. Chem. 268 22243-22246.

64. Gibbs, E., J. Stock, S. McCoid, H. Stukenbrok, J. Pessin, R. Stevenson, A. Milici, and J. McNeish. 1995. Glycemic improvement in diabetic db/db mice by overexpression of the human insulin-regulatable glucose transporter (GLUT4). J. Clin. Invest. 95:1512-1518.

65. Vaag, A., P. Damsbo, O. Hother-Nielsen, and H. Beck-Nielsen. 1992. Hyperglycaemia compensates for the defects in insulin-mediated glucose metabolism and in the activation of glycogen synthase in the skeletal muscle of patients with type 2 (non-insulin-dependent) diabetes mellitus. Diabetologia. 35: 80-88.

66. Rebrin, K., G. Steil, S. Mittelman, and R. Bergman. 1996. Causal linkage between insulin suppression of lipolysis and suppression of liver glucose output in dogs. J. Clin. Invest. 98:741-749.

67. Ader, M., and R. Bergman. 1990. Peripheral effects of insulin dominate suppression of fasting hepatic glucose production. Am. J. Physiol. 258:E1020E1032.

68. Rebrin, K., G. Steil, L. Getty, and R. Bergman. 1995. Free fatty acid as a link in the regulation of hepatic glucose output by peripheral insulin. Diabetes. 44:1038-1045

69. Boden, G., X. Chen, J. Ruiz, J. White, and L. Rossetti. 1994. Mechanisms of fatty acid-induced inhibition of glucose uptake. J. Clin. Invest. 93:24382446 . 